\title{
Struktur Komunitas Mangrove Pesisir Pantai Desa Dalapuli Barat, Bolaang Mongondow Utara
}

\author{
Nurul Auliyah ${ }^{1}$ dan Agus Blongkod ${ }^{2}$ \\ ${ }^{1}$ Staf Pengajar Program Studi Perikanan dan Kelautan Universitas Gorontalo. \\ E-mail : Nurulauliyah05@gmail.com \\ ${ }^{2}$ Staf Dinas Perikanan Kabupaten Bolaang Mongondow Utara
}

\begin{abstract}
Mangrove is one of vegetation on coastal where very important. The aim of research is to know the structure of community of mangrove forests in Dalapuli Barat Village Pinogaluman Sub-district, Bolaang Mongondow Utara District. The method to take the sample in this research is transek square method. The first sample plot is on the left of the path axis and the second sample plot is on the right of the path axis and then alternates. Sampling growth of $2 m \times 2 m$ for the seedling phase, ie regeneration of trees that begin to increase until the power $<1.5 \mathrm{~m}$. Example plots are $5 \mathrm{~m}$ $x 5 \mathrm{~m}$ for the stake, ie high regeneration $>1.5 \mathrm{~m}$ up to $<10 \mathrm{~cm}$ in diameter, and. The sample plot is $10 \mathrm{~m} \times 10 \mathrm{~m}$ for the tree phase, ie trees having a diameter of more than $10 \mathrm{~cm}$. The results of this study are: 8 species of mangrove species are found in Rhyzopora apiculata, Xylocarpus granatum, Cheriops tag, Sonneratia alba, Nypa fruticans, Lumnitzera littorea, pandanus techtorius, and Acanthus ebracteatus The essential tree index value (INP) is 302, Pancang is 302, (scale 0 - 300 and seedling level includes 313. Index diversity of analysis result is low.
\end{abstract}

Keywords : Mangrove, Community, Dalapuli Village 


\section{Pendahuluan}

Hutan mangrove yang ada di Indonesia tersebar di daerah pantai yang terlindungi dan di muara-muara sungai. Indonesia terdiri atas 13,677 pulau memiliki garis pantai sepanjang lebih kurang 3.852.223 km (Bappenas, 2012). Tumbuhan Mangrove tersebut berasosiasi dengan organisme lain (fungi, mikroba, algae, fauna dan tumbuhan lainnya) membentuk komunitas mangrove. Komunitas mangrove tersebut berinteraksi dengan faktor abiotik (iklim, udara, tanah,dan air) membentuk ekosistem mangrove (Sengupta, 2010). Data perkiraan luas areal mangrove di Indonesia sangat beragam sehingga sulit untuk mengetahui secara pasti seberapa besar penurunan luas areal mangrove tersebut.

Hutan mangrove merupakan salah satu ekosistem pesisir tropis atau sub-tropis yang sangat dinamis serta mempunyai produktivitas, nilai ekonomis, dan nilai ekologis yang tinggi (Santoso, 2000) Hutan mangrove sebagai daerah dengan produktivitas yang tinggi memberikan kontribusi besar terhadap detritus organik yang sangat penting sebagai sumber energi bagi biota yang hidup di sekitarnya. (Sugiarto dan Ekariyono. 2003). Hutan mangrove mempunyai fungsi fisik dan fungsi ekologi yang penting bagi kelestarian ekosistem di daerah pesisir. Secara fisik, hutan mangrove berfungsi sebagai pelindung pantai dari pengaruh gelombang laut. Secara ekologi, hutan mangrove menyediakan habitat bagi berbagai macam spesies karena fungsinya sebagai daerah asuhan (nursery ground), daerah pemijahan (spawning ground), serta tempat untuk mencari makan (feeding ground) bagi biota perairan yang terdapat di dalamnya. Berbagai jenis ikan yang bersifat herbivora, omnivora maupun karnivora hidup mencari makan di sekitar mangrove terutama pada waktu air pasang (Gunarto, 2004). Hutan mangrove juga berperan pada ketersediaan produksi makanan dan juga sebagai tempat berlindung dari predator (Nursal, 2005; Kon, 2009).

Penginderaan jauh dapat dimanfaatkan dalam pemantauan komunitas mangrove, hal ini didasarkan atas dua sifat penting yaitu bahwa mangrove mempunyai zat hijau daun (klorofil) dan mangrove tumbuh di pesisir. Sifat optik klorofil sangat khas yaitu bahwa klorofil menyerap spektrum sinar merah dan memantulkan kuat spektrum hijau (Susilo, 2000).

Luas mangrove Sulawesi utara memiliki hutan mangrove seluas 22.370 Ha yang tersebar di kabupaten Gorontalo (BAPPENAS, 2012). Berdasarkan hal tersebut diatas maka dilakukankanlah penelitian ini yang berjudul struktur komunitas mangrove pesisir Pantai desa dalapuli barat, bolaang mongondow utara. 


\section{Metode Penelitian}

\subsection{Waktu dan Tempat}

Penelitian ini dilakukan selama dua Bulan dari Bulan April sampai Mei 2016. Lokasi Penelitian dilakukan di Kawasan Ekosistem Mangrove di pesisir pantai Desa Dalapuli Barat.

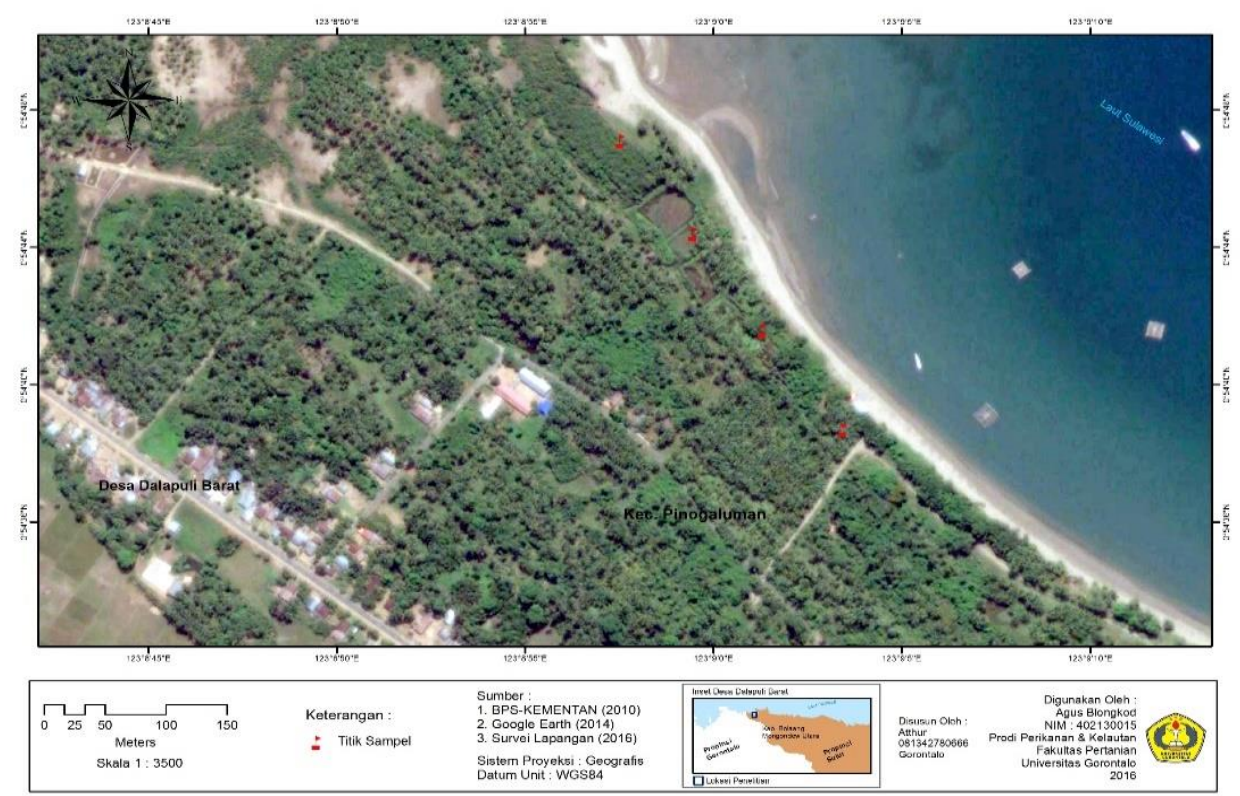

Gambar 1. Peta Lokasi Penelitian

\subsection{Teknik Pengambilan Sampel}

Teknik pengambilan Data contoh dilakukan dengan menggunakan kombinasi jalur dan petak contoh dengan intensitas sampling 4\%, lebar jalur 10 meter atau 5 meter kiri dan kanan sumbu jalur. Jarak antara jalur pengamatan 200 meter dan panjang jalur induk 1000 meter.

Penentuan titik ikat (starting point) dengan menggunakan batas alam yang mudah ditemukan di lapangan, jalur pengamatan dibuat tegak lurus garis pantai dimulai dari titik terluar. Jarak antara petak ukur contoh pada jalur pengamatan 100 meter. Petak contoh pertama berada pada sebelah kiri sumbu jalur dan petak contoh kedua berada pada sebelah kanan sumbu jalur dan selanjutnya berselang-seling. Pengukuran fase pertumbuhan dilakukan dengan membagi petak-petak pada jalur pengamatan ke dalam beberapa petak sebagai berikut :

1. Petak contoh berukuran $2 \mathrm{~m} \times 2 \mathrm{~m}$ untuk fase semai, yaitu permudaan pohon yang mulai bertambah sampai tinggi berukuran $<1,5 \mathrm{~m}$.

2. Petak contoh berukuran $5 \mathrm{~m} \times 5 \mathrm{~m}$ untuk fase pancang, yaitu permudaan yang tingginya $>1,5 \mathrm{~m}$ sampai engan yang berdiameter $<10 \mathrm{~cm}$. 
3. Petak contoh berukuran $10 \mathrm{~m} \times 10 \mathrm{~m}$ untuk fase pohon, yaitu pohonpohon yang memiliki diameter lebih dari $10 \mathrm{~cm}$.

Data yang dikumpulkan berdasarkan tingkat pertumbuhan komunitas mangrove. Fase semai dan pancang data yang dikumpulkan adalah nama jenis dan jumlah individu tiap jenis. Fase pohon data yang dikumpulkan adalah nama jenis, jumlah jenis, tinggi serta diameter pohon. Data lain yang dikumpulkan berupa keadaan untuk lokasi penelitian berupa letak dan luas, tanah dan topografi, iklim, flora, fauna, kondisi demografi dan sosial budaya serta sarana prasarana.

\subsection{Analisis Data}

Data yang dikumpulkan di lapangan diolah secara kuantitatif untuk menghitung kerapatan (K), frekuensi (F), Dominansi (D), dan Indeks Nilai Penting (INP). Suatu jenis pada masing-masing fase pertumbuhan di dasarkan pada rurnus perhitungan analisa vegetasi menurut Soerianegara dan Indrawan, (1983) sebagai berikut:

1. Kerapatan Jenis (Di) adalah jumlah tegakan jenis $i$ dalam suatu unit area Rumus 1

$$
D_{\mathrm{i}}=\frac{\mathrm{n}_{\mathrm{i}}}{\mathrm{A}}
$$

Keterangan:

$\mathrm{D}_{\mathrm{i}}$ : Kerapatan jenis ke- $i$

$\mathrm{n}_{\mathrm{i}}$ : Jumlah total tegakan ke- $i$

A : Luas area total pengambilan contoh

2. Kerapatan relatif $\left(\mathrm{KR}_{\mathrm{i}}\right)$

$$
K R_{\mathrm{i}}=\frac{\mathrm{n}_{\mathrm{i}}}{\sum \mathrm{n}} \mathrm{x} 100 \%
$$

Keterangan :

RDi : Kerapatan relatif jenis ke- $i$

$\mathrm{Ni}$ : Jumlah total tegakan dari jenis ke- $i$

$\Sigma \mathrm{n} \quad$ : Jumlah total tegakan seluruh jenis

3. Frekuensi $\left(\mathrm{F}_{\mathrm{i}}\right)$

$$
F=\frac{\mathrm{P}_{\mathrm{i}}}{\sum \mathrm{p}}
$$

Keterangan:

Fi : Frekuensi jenis ke- $i$

$\mathrm{Pi}$ : Junlah plot ditemukannya jenis ke- $i$

$\Sigma \mathrm{P}:$ Jumlah plot pengamatan 
4. Frekuensi Relatif $\left(\mathrm{FR}_{\mathrm{i}}\right)$

$$
F R_{\mathrm{i}}=\frac{\mathrm{F}_{\mathrm{i}}}{\sum \mathrm{F}} \times 100 \%
$$

Keterangan:

RFi : Frekuensi relative jenis $i$

$\mathrm{Fi}$ : Frekuensi jenis ke- $i$

$\Sigma F:$ Jumlah frekuensi untuk seluruh jenis

5. Dominasi (D) 5

$$
\left.\mathrm{D}=\sum_{i=1}^{S} \frac{\mathrm{n}_{\mathrm{i}}}{\mathrm{N}}\right]
$$

Keterangan:

D : Indeks dominasi Simpson

ni : Jumlah individu spesies ke-i

$\mathrm{N}$ : Jumlah total individu dari semua spesies

$\mathrm{s}$ : Jumlah spesies atau taksa

6. Dominasi Relatif (DR)

$$
D R_{\mathrm{i}}^{\left({ }_{\mathrm{i}}\right.}=\left(\mathrm{DM}(\mathrm{i}) / \sum \mathrm{DM}\right) \times 100 \%
$$

Keterangan :

$\mathrm{DR}_{(\mathrm{i})}=$ Dominansi relatif spensien (i)

$\mathrm{DM}_{(\mathrm{i})}=$ Dominansi mutlak spesies (i)

$\sum \mathrm{DM}=$ Jumlah DM total

7. Indeks Nilai Penting - Untuk tingkat pohon, tiang, pancang dan semai. Nilai penting ini untuk memberikan suatu gambaran mengenai pengaruh atau peranan suatu jenis mangrove dalam ekosistem tersebut. Indeks nilai penting memiliki kisaran antara 0-300 (Saparinto, 2007):

$$
\mathrm{INP}=\mathrm{KR}+\mathrm{FR}+\mathrm{DR}
$$

8. Luas Bidang Dasar (LBDS)

$$
\text { LBDS }=1 / 4 \pi \mathrm{d}^{2}
$$

Keterangan:

LBDS $=$ Luas Bidang Dasar

$\Pi=$ Konstanta $(3,14)$

$\mathrm{d}=$ Diameter pohon.

9. Indeks keanekaragaman Shannon ( Shannon's index ) ( Ludwing dan reynold 1988) digunakan untuk mengetahui keanekaragaman jenis disetiap tingkat pertumbuhan dengan rumus sebagai berikut :

$\mathrm{H}=-\sum(p i$ In $p i)$ dengan $p i=(n i / p i) \ldots$. Rumus 9 
Keterangan : $\mathrm{H}=$ Indeks keanekaragaman Shannon

ni $=$ jumlah individu satu jenis ke-i dalam petak ukur

$\mathrm{N}=$ jumlah total individu dalam petak ukur

Besarnya indeks keanekaragaman jenis menurut Shannon-winer dalam fachrul (2006) berkisar antara $0-7$, di definisikan sebagai berikut :

a. Nilai $\mathrm{H}(>3)$ menunjukan keanekaragaman spesis melimpah tinggi

b. Nilai $\mathrm{H}(2<3)$ menunjukan keanekaragaman spesies sedang

c. Nilai $\mathrm{H}(\mathrm{O}<2)$ menunjukan keanekaragaman spesis rendah

\section{Hasil dan Pembahasan}

\subsection{Struktur Komunitas Mangrove Desa Dalapuli Barat}

Komposisi ekosistem mangrove di Desa Dalapuli Barat terdiri dari beberapa spesies mangrove. Hasil penelitian dilakukan dengan pengamatan pada transek yang sudah ditentukan, dan yang diamati tingkat semai, tingkat pancang dan tingkat pohon. Pengamatan tumbuhan mangrove yang tumbuh di Desa Dalapuli Barat ditemukan 8 jenis spesies mangrove, dapat dilihat pada Tabel 1.

Tabel 1. Jenis-jenis Mangrove yang Ditemukan di Desa Dalapuli Barat Kecamatan Pinogaluman Kabupaten Bolaang Mongondow Utara

\begin{tabular}{|c|c|c|c|}
\hline \multirow[t]{2}{*}{ No } & \multicolumn{3}{|c|}{ Nama } \\
\hline & Jenis & Indonesia & Family \\
\hline 1 & Nypa fruticans & Nipah & Arecaceae \\
\hline 2 & Xylocarpus granatum & $\begin{array}{l}\text { Nyiri, ngiri } \\
\text { abang }\end{array}$ & Meliaceae \\
\hline 3 & Cheriops tagal & Soga tingi & Rhizophoraceae \\
\hline 4 & Soneratia alba & $\begin{array}{l}\text { Bogem, perepat } \\
\text { laut }\end{array}$ & Sonneratiaceae \\
\hline 5 & Rhizopora apiculata & $\begin{array}{l}\text { Bakau, bakau } \\
\text { minyak }\end{array}$ & Rhizophoraceae \\
\hline 6 & Lumnitzera littorea & $\begin{array}{l}\text { Teruntum } \\
\text { merah }\end{array}$ & Combretaceae \\
\hline 7 & pandanus techtorius & Pandan & Pandanaceae \\
\hline 8 & Acanthus ebracteatus & Jeruju putih & Acanthaceae \\
\hline
\end{tabular}

\subsection{Jenis Vegetasi Mangrove Pada Setiap Stasiun}

\section{A. Stasiun 1 (satu)}

Hasil pengukuran data komunitas mangrove di pesisir pantai Desa Dalapuli Barat yang telah dikumpulkan kemudian diolah dan selanjutnya 
dianalisis sesuai dengan data perstasiun, yang ditemukan pada stasiun 1 ditemukan beberapa jenis mangrove diantaranya Rhyzopora apiculata, Xylocarpus granatum, Cheriops tagal dan Pandanus techtorius.

\section{B. Stasiun 2 (dua)}

Pada stasiun pengamatan ini Beberapa jenis mangrove dengan keadaan sekitar stasiun berdekatan dengan aliran sungai, dari stasiun tersebut ditemukan jenis mangrove seperti Xylocarpus granatum, Sonneratia alba, Lumitzera littorea.

\section{Stasiun 3 (Tiga)}

Hasil analisis data vegetasi mangrove dari Pesisir Pantai Desa Dalapuli Barat Kecamatan Pinogaluman Kabupaten Bolaang Mongondow Utara yang disampling menggunakan metode plot bertingkat (Nested Quadrat), pada stasiun 3 ini berbeda, diperoleh satu jenis mangrove yaitu Xylocarpus granatum.

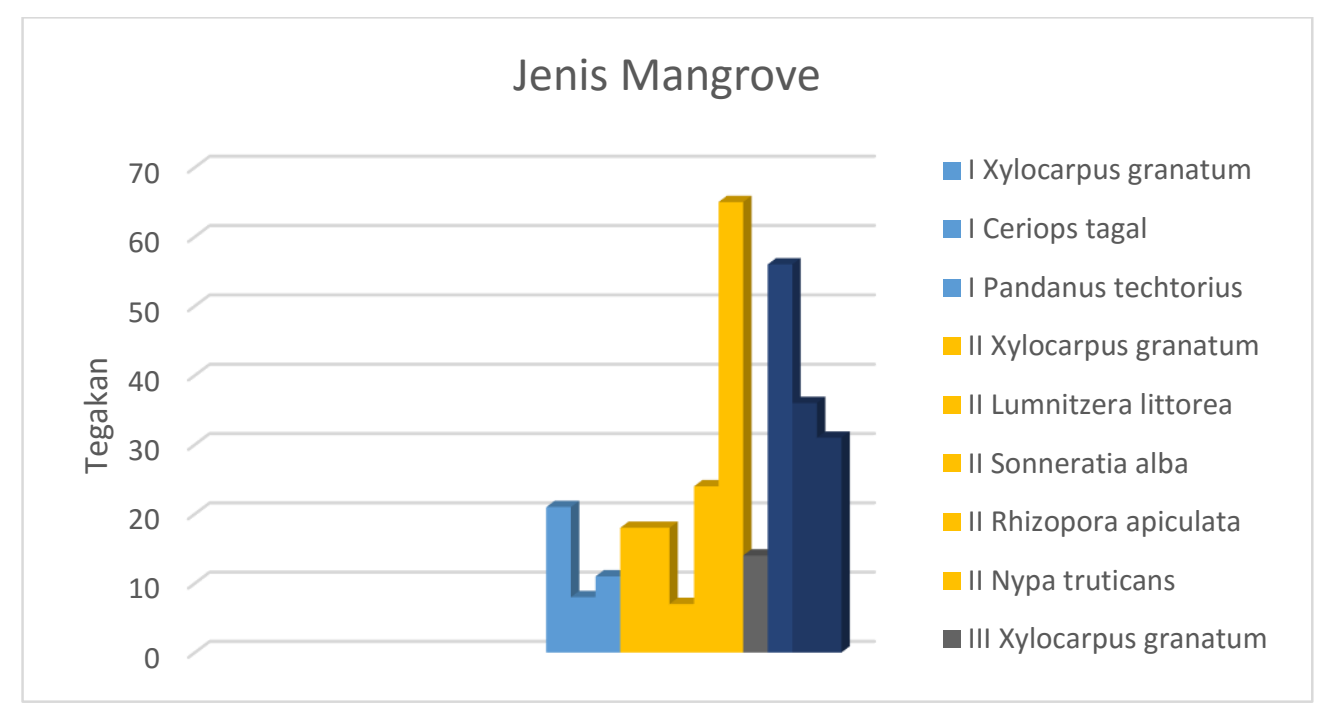

Gambar 2. Jenis vegetasi mangrove

\section{Stasiun 4 (empat)}

Pada stasiun 4 jenis mangrove yang di temukan hanya 3 spesies di antaranya Xylocarpus granatum Lumnitzera littorea dan Acanthus ebracteatus, untuk jenis Acanthus ebracteatus di temukan pada daerah penelitian yang populasi sangat sedikit tidak sesuai dengan keadaan substrat pada dasar yang tempat hidup.

\subsection{Analisis Stuktur Komunitas Vegetasi Mangrove Kategori Pohon}

Hasil analisis dilapangan data yang diperoleh pada 4 stasiun pengamatan, untuk kategori pohon nilai kerapatan relatif yang tertinggi ada pada mangrove jenis Xylocarpus granatum, berkisar antara 37,04\% dan 
terendan dari Cheriops tagal, Sonneratia alba dengan nilai rata-rata 3,70. Sementara untuk nilai frekwensi relative tertinggi adalah Xylocarpus granatum dengan nilai kisaran 40,91\%. Dan frekuensi terendah adalah jenis pandanus techtorius, Sonneratia alba, Nypa fruticans dengan nilai rata-rata 4, 55.

Diagram analisis struktur komunitas mangrove kategori pohon berdasarkan jenis mangrove Desa Dalapuli barat Xylocarpus granatum Nilai yang tertinggi pada Kerapatan Relatif (KR) 37,04 sedangkan yang Nilai yang terendah pada spesies Cheriops tagal, Sonneratia alba pada Kerapatan relatif (KR) rata-rata 3,70, dan Nilai tertinggi pada Fekuensi Relatif (FR) spesies Xylocarpus granatum 40,91 dan Nilai spesies terendah pada Frekuensi Relatif (FR) Sonneratia alba, Nypa fruticans rata-rata 4,55 dan pada spesies Xylocarpus granatum pada Dominasi Relatif (DR). Nilai tertinggi 56,93 dan nilai spesies terendah pada Dominasi Relatif

(DR) Cheriops tagal, Sonneratia alba 0,57.

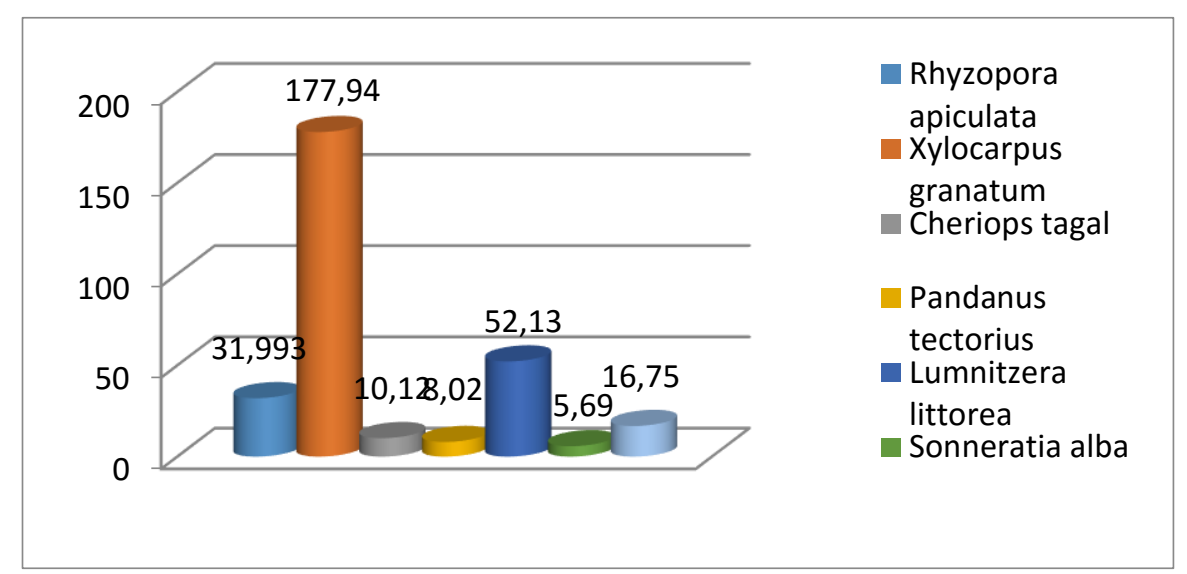

Gambar 3. Indeks nilai penting vegetasi mangrove kategori pohon

\subsection{Struktur Komunitas Mangrove Kategori Pancang}

Analisis struktur komunitas mangrove kategori pancang berdasarkan jenis mangrove di desa dalapuli barat dapat dilihat pada gambar 2. Hasil analisis kategori pancang yang memiiki nilai kerapatan relatif

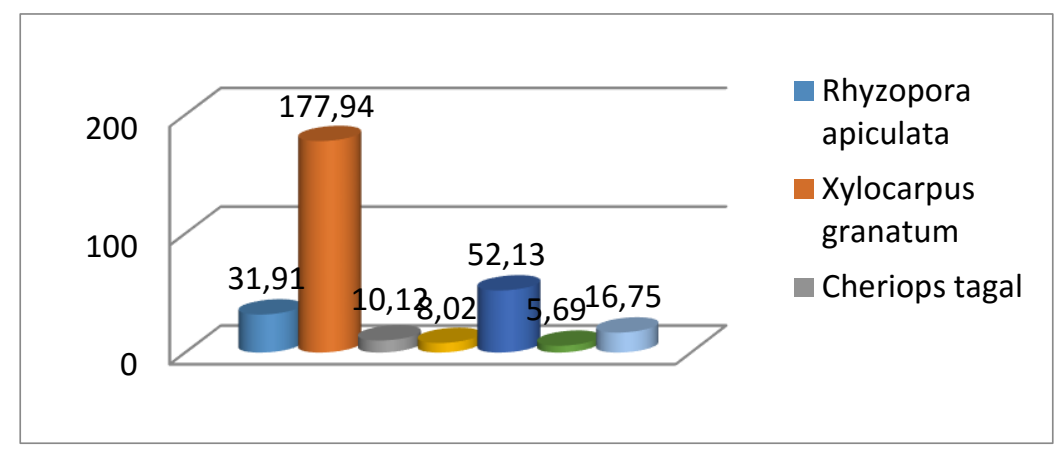

Gambar 4. Indeks nilai penting vegetasi mangrove kategori pancang 
ertinggi yaitu pada jenis Xylocarpus granatum yang memiliki nilai 54,22\% dan terendah adalah Cheriops tagal, Sonneratia alba dengan nilai rata-rata 1,20\% selanjutnya untuk nilai frekuensi relative tertinggi kategori pancang adalah jenis Xylocarpus granatum yaitu $39,13 \%$ dan nilai frekwensi relatif yang terendah adalah spesies mangrove Pandanus tectorius, Sonneratia alba, Nypa fruticans dengan nilai rata-rata 4,35\% dan untuk nilai dominasi relative yang dominan adalah spesis Xylocarpus granatum 83,09\% terendah adalah spesies Cheriops tagal, Sonneratia alba dengan nilai 0,04\%.

\subsection{Analisis Struktur Komunitas Mangrove Kategori Semai}

Kategori semai dari hasil analisis di peroleh nilai Kerapatan relative tertinggi pada spesis Xylocarpus granatum dengan kisaran nilai 38,57\%, selanjutnya Kerapatan relative yang terendah adalah spesis Cheriops tagal 4,29\%, kemudian untuk nilai frekuensi relative yang tertinggi adalah jenis Xylocarpus granatum dengan kisaran 50,00\%, sedangkan terendah adalah spesis Cheriops tagal, Pandanus tectorius, dan Nipa fruticans dengan nilai $5,56 \%$.

\subsection{Analisis Komunitas Vegetasi Mangrove Desa Dalapuli}

Hasil Analisis rekapitulasi struktur Komunitas mangrove Desa Dalapuli Barat indeks nilai penting yang tertinggi adalah spesis Xylocarpus granatum dengan nilai $164,75 \%$ sedangkan yang terendah adalah Sonneratia alba 7,03 $\%$, kemudian untuk nilai Kerapatan relatif tertinggi adalah spesis Xylocarpus granatum dengan nilai $49,04 \%$ dan terendah adalah spesis Sonneratia alba dengan nilai rata-rata $1,92 \%$ dan nilai frekwensi relative tertinggi adalah spesis mangrove Xylocarpus granatum yaitu $28,57 \%$ dan yang terendah spesis mangrove Acanthus ebracteatus dengan nilai rata-rata 2,38\% dan untuk nilai dominasi relative spesis yang mendominasi masi Xylocarpus granatum dengan nilai kisaran $84,95 \%$ sementara terendah adalah Sonneratia alba dengan kisaran nilai rata-rata $0,13 \%$.

\subsection{Indeks Keanekaragaman Mangrove Desa Dalapuli Barat}

Desa Dalapuli Barat merupakan kawasan mangrove pesisir pantai yang seluruh spesies mangrovenya adalah jenis yang mampu beradaptasi dengan salinitas air yang tinggi contohnya jenis Xylocarpus granatum dan, Rhyzopora apiculata. Menurut Noor 1999 merupakan 2 jenis spesis mangrove yang dominan berada pada area yang berhadapan langsung dengan laut atau zona terbuka. Tetapi sesuai pengamatan di lapangan bahwa jenis Xylocarpus granatum merupakan jenis yang paling toleran terhadap salinitas sekitar dengan substrat lumpur bercampur pasir hidup berdekatan dengan mangrove jenis Rhyzopora apiculata yang di temukan dari beberapa plot penelitian. Heddy dan Kurniaty (1996) dalam Suwondo (2006), menambahkan bahwa 
rendahnya keanekaragaman menandakan ekosistem mengalami tekanan atau kondisinya mengalami penurunan. Selain itu rendahnya nilai indeks keanekaragaman mangrove bisa disebabkan karena aktifitas manusia.

Wilayah mangrove Desa Dalapuli Barat merupakan kawasan mangrove pesisir pantai yang seluruh spesis mangrovenya adalah jenis yang mampu beradaptasi dengan salinitas air yang tinggi contohnya jenis Sonneratia alba dan Avicennia lanata, menurut Noor 1999 merupakan 2 jenis spesis mangrove yang dominan berada pada area yang berhadapan langsung dengan laut atau zona terbuka, kemudian di ikuti denga spesis Rhyzopora apiculata, dan Bruguera gymnorhiza, Xylocarpus sp.merupakan spesis mangrove yang berada di dekat darat.

\section{Kesimpulan dan Saran}

\subsection{Kesimpulan}

Berdasarkan pada hasil penelitian yang telah dilakukan di ekosistem mangrove di Desa Dalapuli Barat Kecamatan Pinogaluman Kabupaten Bolaang Mongondow Utara, dapat diambil beberapa kesimpulan sebagai berikut :

1. Struktur komunitas ekosistem mangrove di pesisr pantai Desa Dalapuli Barat mempunyai 8 jenis. Jenis-jenis tersebut adalah Rhyzopora apiculata, Xylocarpus granatum, Cheriops tagal, Lumnitzera littorea, Sonneratia alba, Nypa fruticans dan Acanthus ebracteatus

2. Indeks dominansi adalah Xylocarpus granatum dengan indeks nilai Penting 136,03\%. Pada tingkat pancang jenis mangrove yang paling mendominasi adalah Xylocarpus granatum dengan indeks nilai penting 177,94\%. Sedangkan pada Tingkat semai, jenis yang paling dominan adalah. Xylocarpus granatum dengan indeks nilai penting $170,62 \%$.

3. Indeks Keanekaragaman jenis mangrove Desa Dalapuli Barat adalah $\mathrm{H}=-$ 1.67012, hal ini menunjukan Indeks Keanekaragaman spesis mangrove kurang.

\subsection{Saran}

Perlu adanya penelitian lanjut untuk melihat pola penyebaran Mangrove secara special yang lebih komperehensip. Serta sosialisasi tentang fungsi Mangrove secara ekologi, social, dan ekonomi.

\section{Daftar Pustaka}

Gunarto. 2004. Konservasi Mangrove Sebagai Pendukung Sumber Hayati Perikanan Pantai. Jurnal Litbang Pertanian.

Kusmana dkk, 2008. Manual Silvikultur Mangrove di Indonesia. Dirjen Rehabilitasi lahan dan perhutanan sosial, Departemen Kehutanan, Jakarta, 
Indonesia

Kusmana, C. 2005. Rencana Rehabilitasi Hutan Mangrove dan Hutan Pantai Pasca Tsunami di NAD dan Nias. Makalah dalam Lokakarya Hutan Mangrove Pasca Tsunami, April 2005. Medan.

Kusmana, C, S, Takeda and H, Watanabe., 1994. Litter Production of Mangrove Forest in East Sumatra, Indonesia. Prosidings Seminar V: Ekosistem.

Nursal, Fauziah Y., dan Ismiati. 2005. Struktur Dan Komposisi Vegetasi Mangrove Tanjung Sekodi Kabupaten Bengkalis Riau. Jurnal Biogenesis Vol. 2(1): 1-7 ISSN: 1829-5460.

Noor, Y.R, Khazali, M, dan Suryadiputra, IN. 2006. Panduan Pengenalan Mangrove di Indonesia. Wetlands International. Bogor.

Noor, Y.R., M. Khazali, dan I.N.N. Suryadiputra. 1999. Panduan Pengenalan Mangrove di Indonesia. Bogor: Wetlands International Indonesia Programme. Bogor.

Santoso, N. 2000. Pola Pengawasan Ekosistem Mangrove. Jakarta: Makalah disampaikan pada Lokakarya Nasional Pengembangan Sistem Pengawasan Ekosistem Laut Tahun 2000.

SusiloMartoyo 2000, Manajemen Sumber Daya Manusia ( edisi 4 ), dicetak dan diterbitkan BPFE Yogjakarta.

Soerianegara, I. dan A. Indrawan, 1985. Ekologi Hutan Indonesia. Jurusan Manajemen Hutan, Fakultas Kehutanan IPB. Bogor. 